\title{
PENINGKATAN KEMAMPUAN LITERASI MATEMATIS SISWA MELALUI MODEL BRAIN-BASED LEARNING
}

\author{
Nurul Trijastuti \\ SMK Negeri 1 Tarumajaya, Jl. Ifolia Harapan Indah Ds.Pusaka Rakyat Tarumajaya Bekasi, Indonesia \\ email: nurultuti88@gmail.com
}

\begin{abstract}
Based on the results of a survey in class XI of SMK Negeri 1 Tarumajaya, information was obtained that students are still low in the ability to formulate, use and interpret mathematics in various contexts of problems of daily life efficiently. That means that students' literacy skills need to be improved. This research is a Classroom Action Research (PTS). The location of this research is at SMK Negeri 1 Tarumajaya which is located on Jl. Ifolia Harapan Indah Ds. People's Heritage Tarumajaya Bekasi. The research subjects in this school action research were 36 people in the second semester of SMK Negeri 1 Tarumajaya in the 2021-2022 academic year. The object of the research is the students' mathematical literacy ability. The number of cycles carried out was two, namely Cycle I and Cycle II. Each cycle consists of planning, implementing, observing and reflecting. Based on the results of the Classroom Action Research that has been carried out, it can be concluded that the students' mathematical literacy ability after using the Brain-based Learning model in learning Mathematics of Functional material has proven to have increased, namely the average mathematical literacy ability of students in cycle I, which is 71, increasing to 77 in cycle II.
\end{abstract}

Keywords: Mathematical Literacy Ability, Brain-Based Learning Model

\begin{abstract}
ABSTRAK
Berdasarkan hasil survey di kelas XI SMK Negeri 1 Tarumajaya diperoleh informasi bahwa siswa masih rendah dalam kemampuan untuk merumuskan, menggunakan dan menafsirkan matematika dalam berbagai konteks masalah kehidupan sehari-hari secara efesien. Itu artinya bahwa kemampuan literasi siswa perlu untuk ditingkatkan. Penelitian ini merupakan Penelitian Tindakan Kelas (PTS). Lokasi Penelitian ini adalah di SMK Negeri 1 Tarumajaya yang berlokasi di JI. Ifolia Harapan Indah Ds.Pusaka Rakyat Tarumajaya Bekasi. Subjek penelitian pada penelitian tindakan sekolah ini adalah XI Semester II SMK Negeri 1 Tarumajaya Tahun Akademik 2021-2022 sebanyak 36 orang. Objek Penelitian adalah kemampuan literasi matematis siswa. Jumlah siklus yang dilaksanakan sebanyak dua yaitu Siklus I dan Siklus II. Masing-masing siklus terdiri dari perencanaan, pelaksanaan, pengamatan dan refleksi. Berdasarkan hasil Penelitian Tindakan Kelas yang telah dilaksanakan, maka dapat disimpulkan bahwa kemampuan literasi matematis siswa setelah menggunakan model Brain-based Learning pada pembelajaran Matematika materi Fungsi terbukti mengalami peningkatan yaitu rerata kemampuan literasi matematis siswa siklus I yaitu 71 meningkat menjadi 77 pada siklus II.
\end{abstract}

Kata Kunci: Kemampuan Literasi Matematis, Model Brain-Based Learning

Cara sitasi: Trijastuti, N. (2021). Peningkatan Kemampuan Literasi Matematis Siswa Melalui Model Brain-based Learning. J-KIP (Jurnal Keguruan dan IImu Pendidikan), 2 (3), 53-60. 


\section{PENDAHULUAN}

Pendidikan adalah salah satu tolak ukur yang memberikan dampak besar untuk kemajuan bangsa. Sopiah (Herdiana, Zakiah \& Sunaryo, 2021) menyatakan bahwa pendidikan merupakan hal penting dalam rangka meningkatkan kualitas Sumber Daya Manusia baik dari segi spiritual, intelegensi, maupun skill untuk menunjang kehidupannya. Maka dari itu perlu dilakukan usaha untuk meningkatkan kualitas pendidikan Indonesia yang mengalami penurunan. Hal ini dilihat dari hasil penilaian PISA tahun 2018. Penilaian PISA ini bertujuan untuk mempelajari apakah siswa dapat mengaplikasikan pengetahuan yang dipelajari ke dalam situasi yang ditemui dalam kehidupan sehari-hari terutama pada tiga bidang utama yaitu matematika, sains dan membaca. Hasil penilaian PISA tahun 2018 yaitu kemampuan membaca Indonesia berada di skor 371 sementara negara-negara di OECD berada diangka 487, untuk skor matematika dan sains Indonesia ada di skor 379 dan sains di skor 396, sedangkan untuk negara-negara OECD berada di skor 489 .

Salah satu penyebab dari rendahnya hasil tersebut adalah karena rendahnya tingkat literasi di Indonesia. National Institute for Literacy mendefinisikan bahwa literasi kemampuan individu untuk membaca, menulis, berbicara, berhitung, dan memecahkan masalah sesuai dengan tingkat keahlian yang dibutuhkan oleh pekerjaan, keluarga dan masyarakat (Indrawati, 2020). Berdasarkan hasil survey di kelas XI SMK Negeri 1 Tarumajaya diperoleh informasi bahwa siswa masih rendah dalam kemampuan untuk merumuskan, menggunakan dan menafsirkan matematika dalam berbagai konteks masalah kehidupan sehari-hari secara efesien. Itu artinya bahwa kemampuan literasi siswa perlu untuk ditingkatkan.

Mengingat pentingnya kemampuan literasi matematis, diperlukan usaha dalam rangka mengembangkan kemampuan tersebut. Menurut Kuswidi (2015) bahwa dengan menggunakan Brainbased Learning, maka akan memungkinkan untuk mengembangkan literasi matematis, pada langkah persiapan yang melatih keingintahuan akan merangsang kemampuan menyelidiki dan menafsirkan permasalahan matematika dari berbagai konteks, pada langkah elaborasi akan mengarahkan kepada merumuskan dan menerapkan penalaran secara matematis dan menggunakan konsep, prosedur dan fakta untuk menjelaskan atau memperkirakan permasalahan dan penyelesaiannya.

Berdasarkan uraian berikut, penulis tertarik untuk melakukan penelitian mengenai kemampuan literasi matematis yang berjudul "Peningkatan Kemampuan Literasi Matematis Siswa Melalui Model Brainbased Learning " dengan tujuan penelitian adalah untuk mengetahui peningkatan kemampuan literasi matematis siswa melalui metode demonstrasi melalui model Brain-based Learning di kelas XI SMK Negeri 1 Tarumajaya.

\section{METODE PENELITIAN}

Penelitian ini merupakan Penelitian Tindakan Kelas (PTS). Lokasi Penelitian ini adalah di SMK Negeri 1 Tarumajaya yang berlokasi di Jl. Ifolia Harapan Indah Ds.Pusaka Rakyat Tarumajaya Bekasi. Subjek penelitian pada penelitian tindakan sekolah ini adalah XI Semester II SMK Negeri 1 Tarumajaya Tahun Akademik 2021-2022 sebanyak 36 orang. Objek Penelitian adalah kemampuan literasi matematis siswa. Jumlah siklus yang dilaksanakan sebanyak dua yaitu Siklus I dan Siklus II. Masing-masing siklus terdiri dari perencanaan, pelaksanaan, pengamatan dan refleksi.

\section{HASIL PENELITIAN DAN PEMBAHASAN}

\section{a. Hasil Penelitian Pembelajaran Siklus I}

\section{Analisis Data Postes Pembelajaran Siklus I}

Proses data nilai postes atau nilai hasil akhir siswa (postes) setelah dilakukan pembelajaran dengan menggunakan model Brain-based Learning untuk meningkatkan kemampuan literasi matematis siswa, nilai selengkapnya terdapat pada Tabel 1. 
Tabel 1. Nilai Postes Siklus I

\begin{tabular}{|c|c|c|c|c|c|}
\hline No & $\begin{array}{l}\text { Nama } \\
\text { Subyek }\end{array}$ & $\begin{array}{c}\text { Skor } \\
\text { Posttest }\end{array}$ & No & $\begin{array}{l}\text { Nama } \\
\text { Subyek }\end{array}$ & $\begin{array}{l}\text { Skor } \\
\text { Posttest }\end{array}$ \\
\hline 1 & E-01 & 62,5 & 19 & E-19 & 62,5 \\
\hline 2 & $\mathrm{E}-02$ & 67 & 20 & $\mathrm{E}-20$ & 67 \\
\hline 3 & E-03 & 75 & 21 & $\mathrm{E}-21$ & 62,5 \\
\hline 4 & E-04 & 58 & 22 & E-22 & 62,5 \\
\hline 5 & E-05 & 75 & 23 & E-23 & 62,5 \\
\hline 6 & E-06 & 62,5 & 24 & E-24 & 87,5 \\
\hline 7 & E-07 & 54 & 25 & E-25 & 75 \\
\hline 8 & E-08 & 62,5 & 26 & E-26 & 83 \\
\hline 9 & E-09 & 62,5 & 27 & $\mathrm{E}-27$ & 83 \\
\hline 10 & E-10 & 87,5 & 28 & E-28 & 62,5 \\
\hline 11 & $\mathrm{E}-11$ & 75 & 29 & E-29 & 72,5 \\
\hline 12 & E-12 & 83 & 30 & E-30 & 54 \\
\hline 13 & $\mathrm{E}-13$ & 83 & 31 & E-31 & 87,5 \\
\hline 14 & E-14 & 62,5 & 32 & E-32 & 87,5 \\
\hline 15 & E-15 & 72,5 & 33 & E-33 & 62,5 \\
\hline 16 & E-16 & 54 & 34 & E-34 & 62,5 \\
\hline 17 & $\mathrm{E}-17$ & 87,5 & 35 & E-35 & 67 \\
\hline 18 & E-18 & 87,5 & 36 & E-36 & 75 \\
\hline
\end{tabular}

Keterangan: rerata 71

Berdasarkan Tabel 1, postes rata-rata skor kemampuan literasi matematis siswa adalah 71 dengan demikian berdasarkan kriteria keberhasilan dinyatakan sikus I belum berhasil. Perbandingan nilai pretes dan postes berdasarkan data hasil pretes menunjukan bahwa rerata skor kemampuan literasi matematis siswa sebesar 14. Dengan demikian, dilihat dari hasil postes, secara umum terdapat peningkatan dengan selisih nilai pretes dan postes sebesar 56 .

\section{Refleksi Tindakan Pembelajaran Siklus I}

Berdasarkan hasil postes pada siklus I belum mencapai target karena nilai rata-rata hanya 71 karena kurang dari kriteria keberhasilan yaitu sebesar nilai $\mathrm{KKM}=75$, maka peneliti merefleksi tindakan siklus I untuk diperbaiki pada siklus selenjutnya (siklus II). Refeleksi siklus I sebagai berikut :

1) Pelaksanaan pembelajaran pada aktivitas guru, pada aspek membuka pembelajaran guru belum menyampaikan materi secara garis besar. Pada aspek kegiatan inti, guru kurang melakukan tanya jawab pada saat diskusi dalam mengerjakan Lembar Aktifitas Siswa (LAS).

2) Siswa kurang antusias saat diminta untuk mempresentasikan hasil kerja kelompoknya.

3) Kemampuan literasi matematis siswa baru mencapai 71.

Dengan demikian, untuk pembelajaran siklus II, hal-hal yang perlu diperbaiki dan ditingkatkan adalah sebagai berikut :

a. Pelaksanaan pembelajaran pada aspek membuka pembelajaran guru harus menyampaikan materi secara garis besar. Pada aspek kegiatan inti, guru harus lebih aktif mengajak siswa melakukan tanya jawab agar soal-soal di LAS dapat terjawab dengan benar. 
b. Peneliti perlu memotivasi siswa untuk bangga dengan hasil kerja mereka, sehingga ketika peneliti menugaskan pada siswa untuk membacakan hasil kerjanya, mereka akan tampak antusias berbeda dengan pada saat siklus I yang tercatat hanya satu kelompok yang mau membacakan hasil kerja mereka.

\section{b. Pelaksanaan Pembelajaran Siklus II}

\section{Hasil Postes Pembelajaran Siklus II}

Hasil tes akhir siswa (postes) setelah dilakukan pembelajaran dengan menggunakan model Brain-based Learning maka diperoleh hasil belajar siswa sebagai bagaimana dapat dilihat pada Tabel 2.

Tabel 2. Nilai Postes Siklus II

\begin{tabular}{|c|c|c|c|c|c|}
\hline No & $\begin{array}{l}\text { Nama } \\
\text { Subyek }\end{array}$ & $\begin{array}{c}\text { Skor } \\
\text { Posttest }\end{array}$ & No & $\begin{array}{l}\text { Nama } \\
\text { Subyek }\end{array}$ & $\begin{array}{l}\text { Skor } \\
\text { Posttest }\end{array}$ \\
\hline 1 & E-01 & 73 & 19 & E-19 & 65 \\
\hline 2 & E-02 & 72 & 20 & E-20 & 68,5 \\
\hline 3 & E-03 & 80,5 & 21 & $\mathrm{E}-21$ & 80 \\
\hline 4 & E-04 & 80 & 22 & E-22 & 71,5 \\
\hline 5 & E-05 & 76 & 23 & E-23 & 62,5 \\
\hline 6 & E-06 & 65 & 24 & E-24 & 89,5 \\
\hline 7 & E-07 & 55 & 25 & E-25 & 77 \\
\hline 8 & E-08 & 64 & 26 & E-26 & 90 \\
\hline 9 & E-09 & 63 & 27 & E-27 & 85 \\
\hline 10 & E-10 & 87,5 & 28 & E-28 & 73 \\
\hline 11 & $\mathrm{E}-11$ & 80 & 29 & E-29 & 77 \\
\hline 12 & E-12 & 88 & 30 & E-30 & 70 \\
\hline 13 & E-13 & 87 & 31 & E-31 & 91 \\
\hline 14 & E-14 & 72,5 & 32 & E-32 & 90 \\
\hline 15 & E-15 & 72,5 & 33 & E-33 & 70 \\
\hline 16 & E-16 & 59 & 34 & E-34 & 69 \\
\hline 17 & $\mathrm{E}-17$ & 92 & 35 & E-35 & 80 \\
\hline 18 & E-18 & 90 & 36 & E-36 & 90 \\
\hline
\end{tabular}

Berdasarkan pada Tabel 2, rata-rata skor kemampuan literasi matematis siswa yaitu 77 dengan demikian diategorikan berhasil karena lebih dari nilai $\mathrm{KKM}=75$. Dilihat dari hasil postes, secara umum terdapat peningkatan dengan selisih nilai rata-rata postes siklus I dan siklus postes II sebesar 6 .

\section{Refleksi Tindakan Pembelajaran Siklus II}

Berdasarkan hasil postes siklus II sudah mencapai target karena nilai rata-rata 77. Adapun refeleksi siklus II sebagai berikut : 
a) Pelaksanaan pembelajaran pada aktivitas guru sudah baik sesuai rencana pembelajaran yang telah disusun.

b) Rerata skor kemampuan literasi matematik siswa mencapai rata-rata 77 , hal ini menunjukkan secara keseluruhan sudah mencapai target yang ditetapkan yaitu melebihi nilai KKM $=75$.

Berdasarkan refleksi tersebut, bahwa pembelajaran siklus II, menunjukkan bahwa :

a) Pelaksanaan pembelajaran pada aspek membuka pembelajaran guru telah menyampaikan materi secara garis besar. Pada aspek kegiatan inti, guru aktif mengajak siswa melakukan Tanya jawab agar soal-soal di LAS dapat terjawab dengan benar.

b) Peneliti telah memotivasi siswa untuk bangga dengan hasil kerja mereka, sehingga ketika praktisi menugaskan pada siswa untuk membacakan hasil kerjanya, mereka tampak antusias berbeda dengan pada saat siklus I yang tercatat hanya satu kelompok yang mau membacakan hasil kerja mereka.

Adapun hal-hal yang masih perlu diperbaiki dan ditingkatkan adalah pengalokasian waktu secara proporsional dari setiap langkah-langkah pembelajaran. Pengalokasian waktu harus dihitung dengan matang, sehingga tidak mengganggu proses pembelajaran yang lain.

\section{c. Pembahasan Hasil Penelitian}

Hasil tes kemampuan literasi matematis siswa secara keseluruhan dapat diuraikan dengan membandingkan nilai postes pada tindakan pertama dengan nilai postes pada tindakan kedua. Dari 36 orang siswa, ternyata nilai postes tindakan pertama mendapat nilai rata-rata 71 sedangkan nilai postes tindakan kedua mendapat nilai rata-rata 77 . Perbedaan nilai rata-rata tindakan pertama dengan nilai rata-rata tindakan kedua adalah sebesar 6 hal ini menunjukan adanya perubahan yang lebih baik.

Berdasarkan hasil postes siklus I dan siklus II diperoleh rincian data ketercapaian terhadap kriteria keberhasilan atau KKM $=75$. Pada siklus I yaitu sebanyak 10 orang siswa atau sebesar sebesar 28\% memperoleh skor kemampuan literasi matematis melebihi KKM, sebanyak 5 orang siswa atau sebesar 14\% memperoleh skor kemampuan literasi matematis pas KKM dan sebanyak 21 orang siswa atau sebesar $21 \%$ memperoleh skor kemampuan literasi matematis kurang dari KKM. Pada siklus II yaitu sebanyak 19 orang siswa atau sebesar sebesar $53 \%$ memperoleh skor kemampuan literasi matematis melebihi KKM dan sebanyak 17 orang siswa atau sebesar $47 \%$ memperoleh skor kemampuan literasi matematis kurang dari KKM.

Gambaran umum perbandingan hasil pelaksanaan pembelajaran siklus I dan II selengkapnya dapat dilihat pada Tabel 3.

Tabel 3. Rekafitulasi Hasil Pelaksanaan Siklus I dengan Siklus II

\begin{tabular}{cccc}
\hline \multicolumn{2}{c}{ Aspek Tindakan } & Siklus I & Siklus II \\
\hline \multicolumn{2}{c}{ Rerata total kemampuan literasi matematis } & 71 & 77 \\
siswa & & $28 \%$ & $53 \%$ \\
Rincian ketercapaian terhadap & $>75$ & $14 \%$ & $0 \%$ \\
KKM & $=75$ & $58 \%$ & $47 \%$ \\
\hline
\end{tabular}

Adapun grafik hasil pelaksanaan siklus I dan II adalah sebagai berikut : 


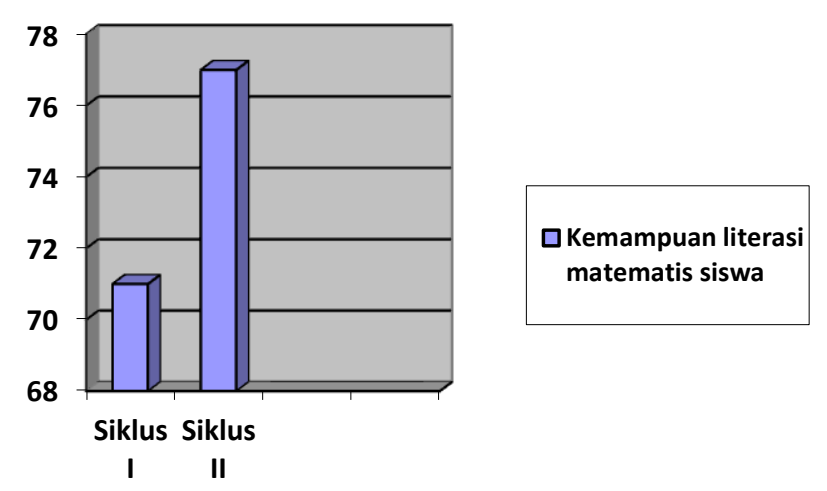

\section{Gambar 1. Perbandingan Rerata Siklus I dan II}

Berdasarkan Gambar 1, diketahui bahwa kemampuan literasi matematis siswa mengalami peningkatan melalui penggunaan model Brain-based Learning . Hasil penelitian ini dikarenakan model Brain-based Learning memiliki kelebihan menurut Jensen (Ibrahim, 2016) menyatakan beberapa kelebihan beberapa kelebihan dari model Brain-based Learning adalah:

a. Menciptakan lingkungan belajar yang menantang kemampuan berpikir siswa.

b. Menciptakan lingkungan pembelajaran yang menyenangkan.

c. Menciptakan situasi pembelajaran yang aktif dan bermakna bagi siswa.

Selain itu terdapat tiga instruksi penting ketika menerapkan Brain-based Learning di kelas menurut Caine et al., (Sukoco, 2014) adalah sebagai berikut:

a. Relaxed alertness, yaitu mengusahakan sebuah keadaan dimana siswa bisa "waspada tapi rileks". Hal tersebut berguna untuk menghilangkan rasa takut pada diri siswa, sambil menjaga lingkungan agar tetap menarik dan menantang baginya.

b. Orchestrated immersion, yaitu menciptakan lingkungan belajar yang benar-benar membuat siswa merasa telah masuk ke dalam pengalaman edukatif secara langsung.

c. Active processing, yakni kegiatan yang memungkinkan siswa secara aktif melihat, mengkondisikan dan menginternalisasi informasi yang datang.

Hasil penelitian ini sejalan dengan penelitian Kuswidi (2015) yang hasil penelitiannya yaitu memungkinkan untuk meningkatkan literasi matematis siswa menggunakan Brain-based Learning . Begitu juga dengan hasil penelitian Sunaryo \& Nuraida (2017) yang hasil penelitiannya yaitu kemampuan pemecahan masalah matematik siswa yang pembelajarannya menggunakan model Brain-based Learning lebih baik daripada siswa yang menggunakan model direct instruction. Kemampuan pemecahan masalah matematik dan literasi matematik sama-sama kemampuan tingkat tinggi sehingga hasil penelitiannya sejalan.

\section{KESIMPULAN}

Berdasarkan hasil Penelitian Tindakan Kelas yang telah dilaksanakan, maka dapat disimpulkan bahwa kemampuan literasi matematis siswa setelah menggunakan model Brain-based Learning pada pembelajaran Matematika materi Fungsi terbukti mengalami peningkatan yaitu rerata kemampuan literasi matematis siswa siklus I yaitu 71 meningkat menjadi 77 pada siklus II di kelas XI semester II SMK Negeri 1 Tarumajaya. 


\section{REKOMENDASI}

Pada tahap pengerjaan Lembar Aktifitas Siswa (LAS) sebaiknya siswa betul-betul memotivasi siswa untuk berdiskusi secara kelompok serta memberikan bantuan saat siswa mengalami kesulitan dalam menjawab soal-soal LAS.

\section{UCAPAN TERIMAKASIH}

Ucapan terimakasih penulis tujukan kepada pihak-pihak yang telah membantu dalam penelitian ini yaitu siswa kelas XI semester II SMK Negeri 1 Tarumajaya tahun akademik 2021-2022.

\section{DAFTAR PUSTAKA}

Herdiana, L., Zakiah, N. E., \& Sunaryo, Y. (2021). Penerapan Model Pembelajaran Diskursus Multy Reprecentacy (DMR) terhadap Kemampuan Pemahaman Matematis Siswa. J-KIP (Jurnal Keguruan dan IImu Pendidikan), 2 (1), 9-14.

Ibrahim, D. (2016). Pengaruh model pembelajaran brain based learning terhadap aktivitas belajar PAI $\begin{array}{llllll}\text { siswa. } & 1 & \text { [2], } & \text { 164-179. Jurnal } & \text { Atthulab. }\end{array}$ https://journal.uinsgd.ac.id/index.php/atthulab/article/download/2525/2502

Indrawati, F. (2020). Peningkatan kemampuan literasi matematika di era revolusi industri 4.0. 1 [1], 382386. Prosiding Seminar Nasional Sains. Tersedia: http://proceeding.unindra.ac.id/index.php/sinasis/article/view/4064

Kuswidi, I. (2015). Brain-based Learning untuk meningkatkan literasi matematis siswa. E-jurnal Al-Jabar: Jurnal Pendidikan Matematika. 6[2], $195 \quad$ - $202 . \quad$ Tersedia: http://ejournal.radenintan.ac.id/index.php/al-jabar/article/view/49

Organization for Economic Co-Operation and Development (OECD). (2018). PISA 2021 mathematics framework.Tersedia.https://pisa2021-

maths.oecd.org/files/PISA\%202021\%20Mathematics\%20Framework\%20Draft.pdf

Sukoco, H. (2014). Efektivitas pendekatan brain-based learning (BBL) ditinjau dari kemampuan komunikasi matematis siswa. Jurnal AgriSains, 2 [5], 148-165. Tersedia: https://ejurnal.mercubuanayogya.ac.id/index.php/Agrisains/article/view/124

Sunaryo, Y., \& Nuraida I. (20017). Pengaruh penerapan model pembelajaran Brain-based Learning terhadap kemampuan pemecahan masalah matematik siswa. E-Jurnal Penelitian Pendidikan dan Pengajaran Matematika, 3[2], 89-96. Tersedia: jurnal.unsil.ac.id/index.php/jp3m 
